\title{
An Ecological Study of Lung Cancer Mortality and Severe Air Pollution in the 1960s in an Industrial City in Japan
}

\author{
Masayuki Shima* and Yoshiko Yoda \\ Department of Public Health, Hyogo College of Medicine, 1-1 Mukogawa-cho, Nishinomiya, Hyogo 663-8501, Japan \\ *Corresponding author. Tel: +81-798-45-6565, E-mail: shima-m@hyo-med.ac.jp
}

\begin{abstract}
This study aimed at assessing the association between exposure to severe air pollution in the past and the subsequent transition in lung cancer mortality among persons who lived in an industrial city. Vital statistics from 1983 to 2006 and the data on air pollution measurements from 1960 to 1990 in Amagasaki City, Japan, were used. Pearson correlation coefficients were calculated between the standardized mortality ratios (SMRs) for lung cancer and the air pollution levels in 6 wards of Amagasaki City. The associations between changes in air pollution levels and the annual SMRs were also evaluated in the light of a potential latency period. The levels of air pollution were extremely high in the 1960s, and they decreased since 1970. The SMRs for lung cancer in 1989-1993 among females for 6 wards were significantly associated with the amounts of both sulfur oxides and dust fall in the past for each ward. The positive associations were observed between the annual SMRs among females and the amounts of both pollutants when the lag time of 20-30 years was taken into account. These results suggest that severe air pollution in the 1960s in an industrial city affected the subsequent increase in lung cancer mortality.
\end{abstract}

Key words: Air pollution, Sulfur oxides, Dust fall, Lung cancer, Standardized mortality ratio

\section{INTRODUCTION}

In Japan, lung cancer mortality has been consistently increasing since the 1950s (Marugame and Sobue, 2004). Numerous epidemiological studies have consistently reported smoking as a major risk factor for lung cancer (Marugame et al., 2005; Doll et al., 1994; Stevens and Moolgavkar, 1984). On the other hand, varius ecological studies reported that lung cancer mortality was higher in urban districts than in rural districts (Nawrot et al., 2007; Iwai et al., 2005; Archer, 1990;
Buffler et al., 1988; Shimizu et al., 1979; Henderson et al., 1975), and adverse effects of air pollution on lung cancer have been suggested (Cohen and Pope, 1995).

Recently, a prospective cohort study by the American Cancer Society (Pope et al., 2002) reported that high concentrations of air pollutants were significantly associated with the increase in lung cancer mortality. However, European epidemiological studies have not shown a clear association between air pollution and lung cancer (Vineis et al., 2006; Filleul et al., 2005; Hoek et al., 2002; Barbone et al., 1995). Thus, the available epidemiologic evidence is discordant, and the effect of air pollution on lung cancer is not conclusive (Gallus et al., 2008).

It is generally agreed that the latency period from exposure to smoking to occurrence of lung cancer is about 20-30 years (Thun et al., 1997; Doll et al., 1994). In many industrial cities in Japan and in Western countries, the levels of air pollutants were considerably higher in the past several decades (Committee on Japan's Experience in the Battle against Air Pollution; Chairman: Sawa, 1997). If the period from exposure to air pollution to occurrence of lung cancer is similar to the period for smoking, we should consider the possibility that the incidence of lung cancer may increase even if the levels of air pollution have decreased. However, most of the previous epidemiological studies have only compared lung cancer mortality in relation to different levels of air pollution (Gallus et al., 2008; Cohen and Pope, 1995). Few studies have evaluated the long-term transition in lung cancer mortalities in relation to the change in air pollution levels (Filleul et al., 2005; Stevens and Moolgavkar, 1984).

Amagasaki is an industrial city located in Western Japan. The levels of air pollutants, such as sulfur oxides and dust fall, in the city were extremely high from the later 1950s to the 1960s. Thereafter, various pollution control measures were taken in the 1970s, and the levels of both pollutants decreased considerably (Committee on Japan's Experience in the Battle against Air Pollution; Chairman: Sawa, 1997). In the present study, 
the data on air pollution measurements and vital statistics of Amagasaki City were used to evaluate the associations between changes in air pollution levels for several decades and the subsequent transition in lung cancer mortality.

\section{METHODS}

Amagasaki City was chosen to evaluate the effects of air pollution in the past on the transition in lung cancer mortality, because the levels of air pollution have changed dramatically during the past several decades. The city is located in the center of Hanshin industrial zone in Western Japan and faces Osaka Bay. Its population is about 460,000 (2008), and its area is about 49.8 square kilometers. The city is divided municipally into 6 wards (Fig. 1). In the southern coastal district (A, B, and C Wards), many factories, such as steel mills, power plants, and oil refinery plants, were located, and the levels of air pollutants exhausted from the factories used to be extremely high. On the other hand, the northern district (D, E, and F Wards) was a residential zone, although there were a few small-scale factories.

The amounts of sulfur oxides were monitored using the lead dioxide $\left(\mathrm{PbO}_{2}\right)$ method at various stations in the city from 1960 through 1992 (Department of Environment, 1961-1993). The average amounts of sulfur oxides measured at 3-9 stations for each ward were calculated by year. In addition, the concentrations of sulfur dioxide have been continuously monitored using the electrical conductivity method at ambient air monitoring stations in 4 wards since 1969. The average amounts of sulfur oxides (1960-1969) by the $\mathrm{PbO}_{2}$ method in 4 wards strongly correlated with the concentrations of sulfur dioxides by the electrical conductivity method(1969-1973) in the corresponding wards $\left(\mathrm{R}^{2}=0.989\right)$. The amounts of dust fall have been measured using the deposit gauge method at 1-5 stations in each ward since 1959 (Department of Environment, 1961-1993). The annual average amounts of dust fall for each ward were calculated in the same manner as for sulfur oxides. However, the amounts of dust fall for every ward were measured only until 1962.

The vital statistics of Amagasaki City for the 24year period from 1983 to 2006 (Health and Welfare Bureau, 1985-2008), which were officially published by the municipal office, were used to observe lung cancer mortality [the International Classification of Diseases, ninth revision (ICD-9): 162 in 1983-1994; ICD-10: C33-C34 in 1995-2006]. The population and the number of deaths from lung cancer by ward and year were calculated using the officially published

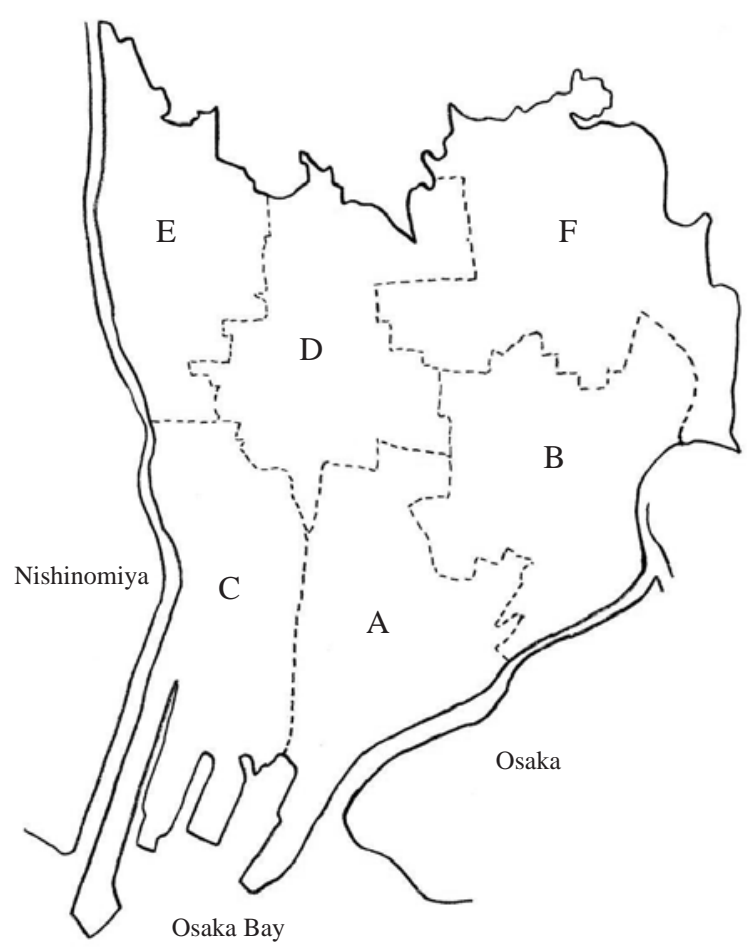

Fig. 1. Locations of the six wards in Amagasaki City, Japan.

data, except for 1999, when the number of deaths by ward was not published. The standardized mortality ratio (SMR) was used to estimate lung cancer mortality by ward and year. Expected deaths in each year and ward were calculated using a sex- and 5-year agespecific population and the corresponding national mortality for lung cancer in each year. The SMRs for each ward were calculated for four periods (1983-1988, 1989-1993, 1994-1998, and 2000-2006), because the number of annual deaths for lung cancer is small (average: 24.6 in males, 9.3 in females). Pearson correlation coefficients were obtained to evaluate the association between the SMRs for lung cancer in each period and the amounts of sulfur oxides and dust fall in the 1960s, when the levels of air pollution were extremely high.

In addition, to evaluate the transition in lung cancer mortality for several decades, the annual SMRs were calculated from 3-year moving averages of observed and expected deaths for the whole city, the northern district, and the southern district. To assess the potential of a latency period from the time of exposure to air pollution to the occurrence of lung cancer, a lag time of 15-30 years was considered, and Pearson correlation coefficients between the annual SMRs and the annual average amounts of sulfur oxides and dust fall in the past were calculated.

All statistical analyses were performed using SPSS 
(A) Sulfur oxides

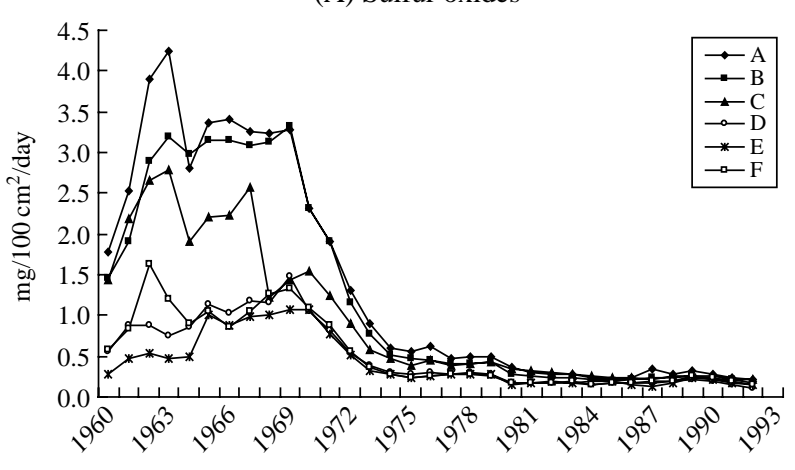

(B) Dust fall

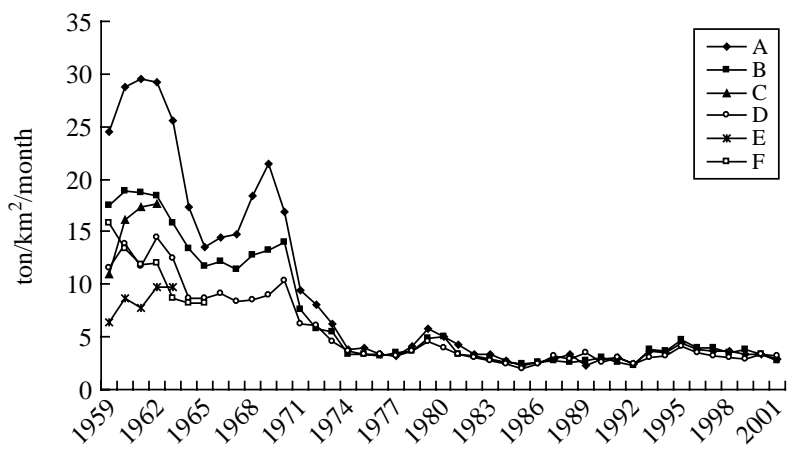

Fig. 2. Annual averages of the amounts of sulfur oxides (A) and dust fall (B) in the six wards in Amagasaki City.

15.0 software (SPSS Inc., Chicago, IL, USA).

\section{RESULTS}

The annual average amounts of sulfur oxides and dust fall in Amagasaki City are shown in Fig. 2. The amounts of sulfur oxides were high in the 1960s in all wards, particularly in A, B, and C Wards. The amounts began to decrease in all wards in about 1970, and no difference among the wards has been observed since 1980. The amounts of dust fall were also high in the 1960 s, but they decreased markedly since 1970. Although the amounts of dust fall were highest in A Ward through the 1960s, the difference among the wards was smaller than that for the sulfur oxides.

The crude mortality rates for lung cancer in Amagasaki City are shown in Fig. 3 with nationwide data. The 3-year moving averages of the crude mortality rates are shown for Amagasaki City. The mortality rates for lung cancer in Japan have consistently increased among both males and females. The rates in Amagasaki City are similar to those in Japan, and they are higher among both males and females than those in

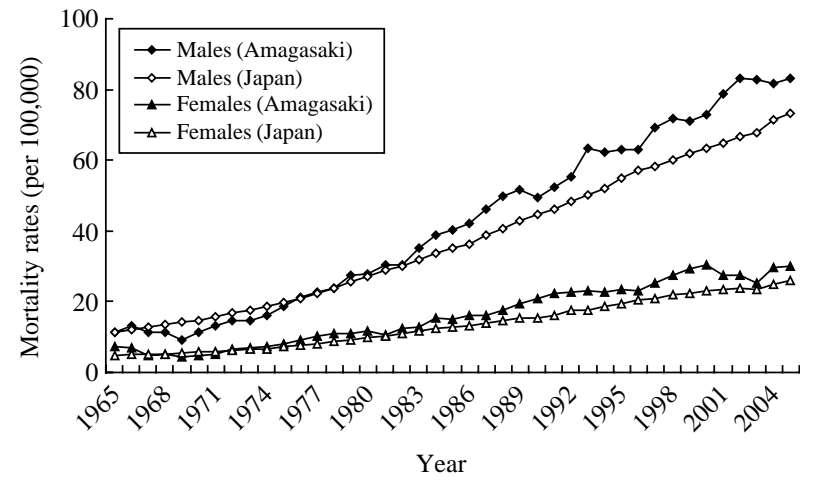

Fig. 3. Time trend of crude mortality rates due to lung cancer in Amagasaki City and Japan. The 3-year moving averages of crude mortality rates are shown for Amagasaki City.

Japan since 1980 .

Table 1 shows the observed numbers of deaths, SMRs, and their 95\% confidence intervals (CIs) for lung cancer in Amagasaki City, by sex, ward, and period. The SMRs for the whole city were significantly higher among both males and females for all periods. For each ward, the SMRs were higher than 1, except for those among females in E Ward in 2000-2006, and most of them were significant among males. The SMRs among females in 1989-1993 were considerably higher for A and B Wards (1.69 [95\%CI: 1.23-2.15] and 1.76 [95\% CI: $1.32-2.19]$ respectively).

Fig. 4 shows the correlations between the SMRs for lung cancer and the amounts of sulfur oxides and dust fall for each ward in the 1960s, when the levels of air pollution were extremely high. The amounts of dust fall were used for 1959-1962, because the amounts for every ward were obtained only during those years. Among females in 1989-1993, the correlation coefficients of the SMRs with the amounts of sulfur oxides (0.929) and dust fall $(0.850)$ were statistically significant (Table 2). However, the SMRs in the other periods were not correlated with the amounts of either sulfur oxides or dust fall. Among males, no correlations were observed between the SMRs and the amounts of air pollutants in any periods.

The transitions in the annual SMRs for lung cancer, which were calculated from 3-year moving averages of observed and expected deaths, are shown in Fig. 5. Among males, the SMRs ranged from 1.19 to 1.52 , and from 1.14 to 1.52 for the southern and northern districts, respectively. The SMRs varied in cycles of several years in both districts. Among females, they ranged from 1.18 to 1.82 , and from 1.04 to 1.37 for the southern and northern districts, respectively. For most of the years, the SMRs were higher in the southern district than in the northern district. In parti- 
Table 1. Observed numbers of deaths and standardized mortality ratios (SMRs) for lung cancer in Amagasaki City.

\begin{tabular}{|c|c|c|c|c|c|c|c|c|}
\hline \multirow[b]{2}{*}{ District } & \multicolumn{2}{|c|}{ 1983-1988 } & \multicolumn{2}{|c|}{ 1989-1993 } & \multicolumn{2}{|c|}{ 1994-1998 } & \multicolumn{2}{|c|}{ 2000-2006 } \\
\hline & $\begin{array}{c}\text { Observed } \\
\text { deaths }\end{array}$ & SMR $(95 \% \mathrm{CI})$ & $\begin{array}{c}\text { Observed } \\
\text { deaths }\end{array}$ & SMR (95\%CI) & $\begin{array}{l}\text { Observed } \\
\text { deaths }\end{array}$ & SMR (95\%CI) & $\begin{array}{l}\text { Observed } \\
\text { deaths }\end{array}$ & SMR (95\%CI) \\
\hline \multicolumn{9}{|l|}{ Males } \\
\hline $\mathrm{A}$ & 108 & $1.33(1.08-1.58)$ & 104 & $1.29(1.04-1.54)$ & 124 & $1.38(1.14-1.62)$ & 186 & $1.34(1.14-1.53)$ \\
\hline B & 137 & $1.45(1.20-1.69)$ & 118 & $1.22(1.00-1.44)$ & 154 & $1.35(1.14-1.57)$ & 237 & $1.29(1.13-1.46)$ \\
\hline $\mathrm{C}$ & 109 & $1.40(1.14-1.67)$ & 100 & $1.22(0.98-1.46)$ & 111 & $1.16(0.94-1.37)$ & 213 & $1.42(1.23-1.61)$ \\
\hline $\mathrm{D}$ & 111 & $1.02(0.83-1.21)$ & 147 & $1.27(1.07-1.48)$ & 171 & $1.23(1.04-1.41)$ & 278 & $1.20(1.06-1.34)$ \\
\hline $\mathrm{E}$ & 67 & $1.30(0.99-1.62)$ & 83 & $1.39(1.09-1.69)$ & 109 & $1.44(1.17-1.71)$ & 175 & $1.28(1.09-1.47)$ \\
\hline $\mathrm{F}$ & 106 & $1.48(1.20-1.76)$ & 104 & $1.32(1.07-1.58)$ & 131 & $1.34(1.11-1.57)$ & 203 & $1.20(1.04-1.37)$ \\
\hline Northern district & 284 & $1.23(1.08-1.37)$ & 334 & $1.32(1.18-1.46)$ & 411 & $1.31(1.19-1.44)$ & 656 & $1.22(1.13-1.32)$ \\
\hline Southern district & 354 & $1.40(1.25-1.54)$ & 322 & $1.24(1.11-1.38)$ & 389 & $1.30(1.17-1.43)$ & 636 & $1.35(1.24-1.45)$ \\
\hline Total & 638 & $1.31(1.21-1.42)$ & 656 & $1.28(1.18-1.38)$ & 800 & $1.31(1.21-1.40)$ & 1292 & $1.28(1.21-1.35)$ \\
\hline \multicolumn{9}{|l|}{ Females } \\
\hline $\mathrm{A}$ & 39 & $1.27(0.87-1.67)$ & 51 & $1.69(1.23-2.15)$ & 42 & $1.24(0.86-1.61)$ & 60 & $1.15(0.86-1.44)$ \\
\hline B & 48 & $1.36(0.97-1.74)$ & 63 & $1.76(1.32-2.19)$ & 56 & $1.31(0.96-1.65)$ & 103 & $1.46(1.18-1.75)$ \\
\hline $\mathrm{C}$ & 44 & $1.59(1.12-2.06)$ & 39 & $1.37(0.94-1.80)$ & 49 & $1.46(1.05-1.86)$ & 82 & $1.51(1.18-1.84)$ \\
\hline $\mathrm{D}$ & 49 & $1.27(0.91-1.62)$ & 51 & $1.24(0.90-1.58)$ & 53 & $1.06(0.77-1.34)$ & 102 & $1.19(0.96-1.42)$ \\
\hline $\mathrm{E}$ & 25 & $1.31(0.80-1.82)$ & 22 & $1.01(0.59-1.43)$ & 37 & $1.30(0.88-1.72)$ & 45 & $0.88(0.63-1.14)$ \\
\hline $\mathrm{F}$ & 36 & $1.37(0.92-1.81)$ & 39 & $1.34(0.92-1.76)$ & 55 & $1.52(1.12-1.92)$ & 82 & $1.33(1.04-1.62)$ \\
\hline Northern district & 110 & $1.31(1.06-1.55)$ & 112 & $1.22(0.99-1.44)$ & 145 & $1.26(1.06-1.47)$ & 229 & $1.16(1.01-1.30)$ \\
\hline Southern district & 131 & $1.40(1.16-1.64)$ & 153 & $1.62(1.36-1.87)$ & 147 & $1.33(1.12-1.55)$ & 245 & $1.38(1.21-1.56)$ \\
\hline Total & 241 & $1.36(1.18-1.53)$ & 265 & $1.42(1.25-1.59)$ & 292 & $1.30(1.15-1.44)$ & 474 & $1.26(1.15-1.38)$ \\
\hline
\end{tabular}

cular, the values in the southern district were markedly higher in 1989-1995.

The lag time of 15-30 years was considered as the potential latency period from the time of exposure to air pollution to the occurrence of lung cancer. Pearson correlation coefficients between the annual SMRs and the annual average amounts of sulfur oxides (Table 3) and dust fall (Table 4) were calculated. Among males, the SMRs in the whole city were not associated with the amounts of either sulfur oxides or dust fall after considering the lag time of 15-30 years. Among males in the northern district, the SMRs were positively associated with the amounts of dust fall for 24- to 26-year lags. Among females, the SMRs in the whole city were positively associated with the amounts of sulfur oxides for 21- to 30-year lags and dust fall for 20- to 23 -year and 28- to 30-year lags. In both the southern and northern districts, most of the associations between the SMRs and the amounts of air pollutants were positive after considering a lag time of 15-30 years, and some of them were statistically significant.

\section{DISCUSSION}

The present study showed that lung cancer mortality increased since 1980 in Amagasaki City, in which the air pollution levels were extremely high from the later 1950 s to the 1960s. After considering the lag time of
20-30 years from the time of exposure to air pollution to the occurrence of lung cancer, positive associations were observed between the annual SMRs for lung cancer among females and the amounts of both sulfur oxides and dust fall, especially in the southern district of the city where the levels of air pollution were markedly higher.

Some epidemiological studies have suggested an association between lung cancer and air pollution (Nafstad et al., 2003; Nyberg et al., 2000; Jedrychowski et al., 1990; Shimizu et al., 1979). In the ACS study (Pope et al., 2002), long-term exposure to fine particulate air pollution was reported to be a risk factor for lung cancer, after adjustment for confounding factors including smoking. Other cohort studies observed a slightly increased mortality for lung cancer in communities with high levels of air pollution (Naess et al., 2007; Laden et al., 2006; Pope et al., 2002; Dockery et al., 1993), although most of them were not statistically significant. European epidemiological studies have not shown a clear association between lung cancer and air pollution (Vineis et al., 2006; Filleul et al., 2005; Hoek et al., 2002; Barbone et al., 1995), but there have been uncertainties about latency from the time of exposure to occurrence (Gallus et al., 2008).

Smoking has been confirmed to be the greatest risk factor for lung cancer (Marugame et al., 2005; Doll et al., 1994; Stevens and Moolgavkar, 1984). The latency period from exposure to smoking to occurrence of lung 
(A) SMR during 1983-1988
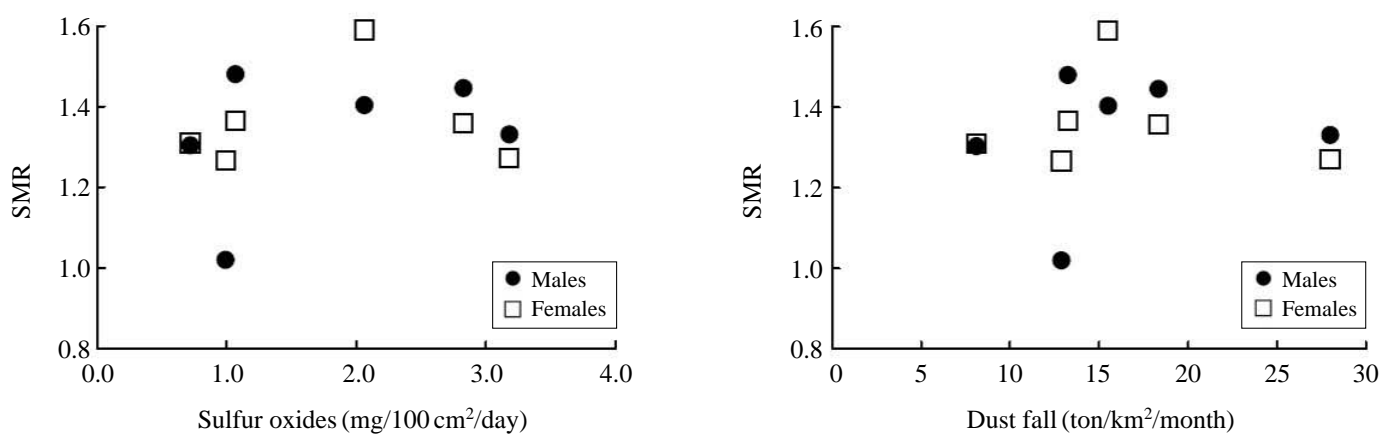

(B) SMR during 1989-1993
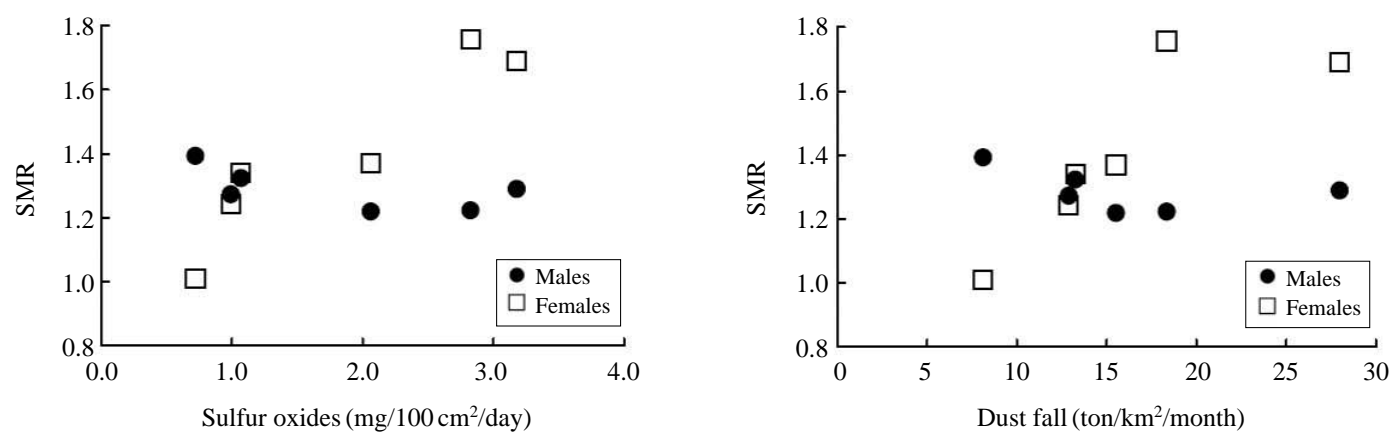

(C) SMR during 1994-1998
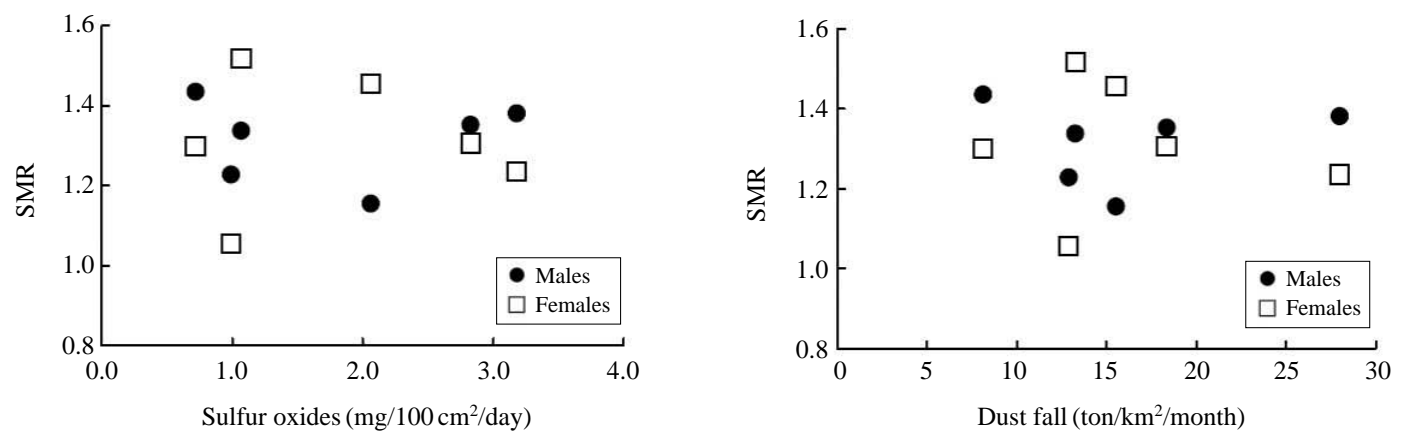

(D) SMR during 2000-2006
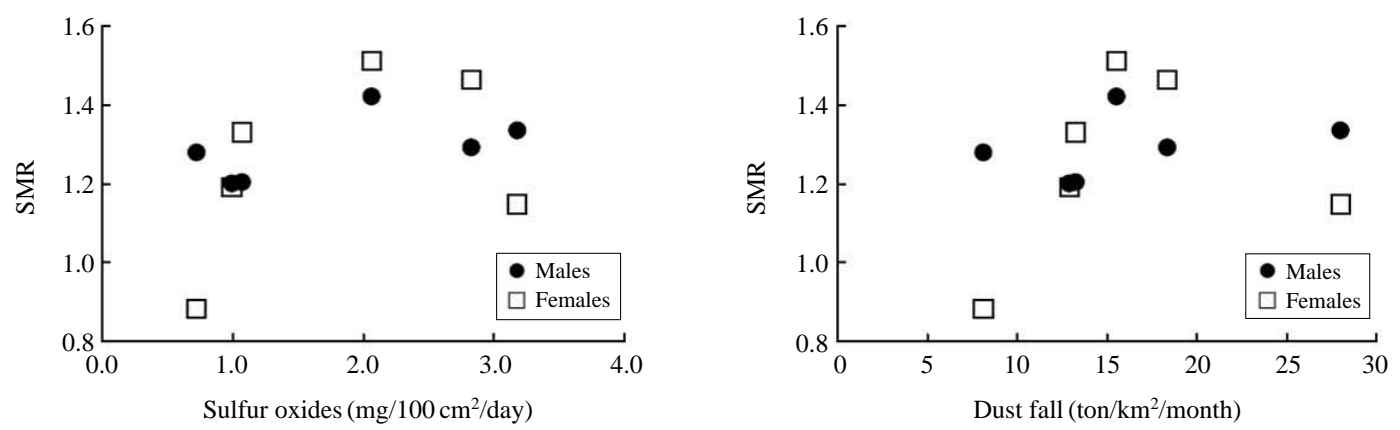

Fig. 4. Correlation between standardized mortality ratios (SMRs) for lung cancer and air pollution. The SMRs for lung cancer and the amounts of sulfur oxides (1960-1969) or dust fall (1959-1962) are shown. 
Table 2. Correlation coefficient between standardized mortality ratios (SMRs) for lung cancer and air pollution in the past.

\begin{tabular}{lrrrrc}
\hline \multirow{2}{*}{ Period } & \multicolumn{2}{c}{$\begin{array}{c}\text { Correlation coefficients } \\
\text { with sulfur oxides }\end{array}$} & \multicolumn{2}{c}{$\begin{array}{c}\text { Correlation coefficients } \\
\text { with dust fall amounts }\end{array}$} \\
\cline { 2 - 3 } Males & \multicolumn{1}{c}{$\mathrm{r}$} & $\mathrm{p}$ & & $\mathrm{r}$ & $\mathrm{p}$ \\
\hline $1983-1988$ & 0.364 & 0.478 & & 0.184 & 0.727 \\
$1989-1993$ & -0.617 & 0.192 & & -0.442 & 0.381 \\
$1994-1998$ & 0.022 & 0.967 & & 0.062 & 0.907 \\
2000-2006 & 0.568 & 0.239 & & 0.384 & 0.452 \\
\hline Females & & & & \\
$1983-1988$ & 0.089 & 0.867 & & -0.134 & 0.800 \\
$1989-1993$ & 0.929 & 0.007 & & 0.850 & 0.032 \\
$1994-1998$ & -0.003 & 0.995 & & -0.120 & 0.821 \\
$2000-2006$ & 0.442 & 0.380 & & 0.255 & 0.626 \\
\hline
\end{tabular}

Correlation coefficient of the SMRs for lung cancer by sex, ward, and period with the amounts of sulfur oxides (1960-1969) or dust fall (1959-1962) are shown.

cancer is considered to be several decades (Doll et al., 1994; Stevens and Moolgavkar, 1984). Therefore, we should consider a similar latency period to estimate the association between air pollution and lung cancer. However, most previous epidemiological studies have compared lung cancer mortality among areas with different levels of air pollution. Only a few studies have reported the transition in lung cancer mortality in a certain area in relation to the change in air pollution levels (Parodi et al., 2005; Archer, 1990; Stevens and Moolgavkar, 1984). Archer (1990) reported that lung cancer mortality increased within about 15 years after an increase in air pollution by a steel mill, and the increase in lung cancer mortality has persisted. In another study, Stevens and Moolgavkar (1984) found that lung cancer incidence among nonsmoking males in England and Wales was coincident with substantial declines in levels of sulfur dioxide and particulate matter.

In the present study, the data on past air pollution measurements and vital statistics in a Japanese industrial city were used to estimate the transition in lung cancer mortality in relation to changes in air pollution levels. The concentrations of air pollutants in the city were very high in the 1960 s, especially in the southern district of the city, and the concentrations decreased markedly since 1970 . The SMRs among females were higher in the southern district than in the northern district, and the peak was observed in 1989-1995. The SMRs were significantly associated with the amounts of sulfur oxides and dust fall for 20- to 30-year lags. In addition, the SMRs in 1989-1993 among females for 6 wards were positively correlated with the amounts of sulfur oxides and dust fall in the past. These find-
(A) SMR among males

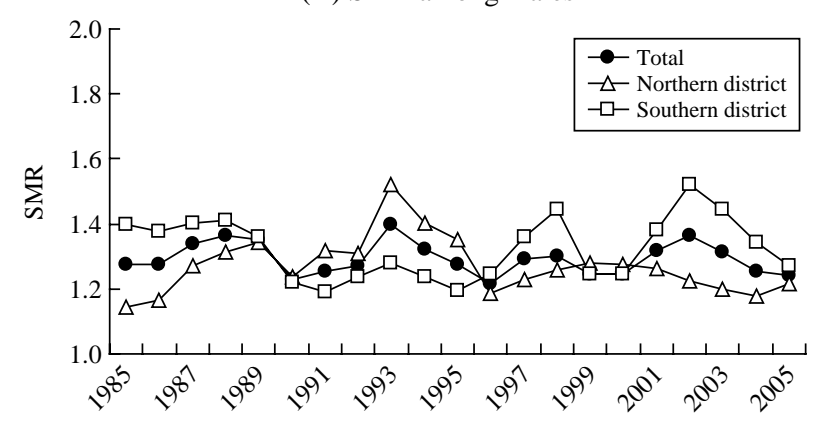

(B) SMR among females

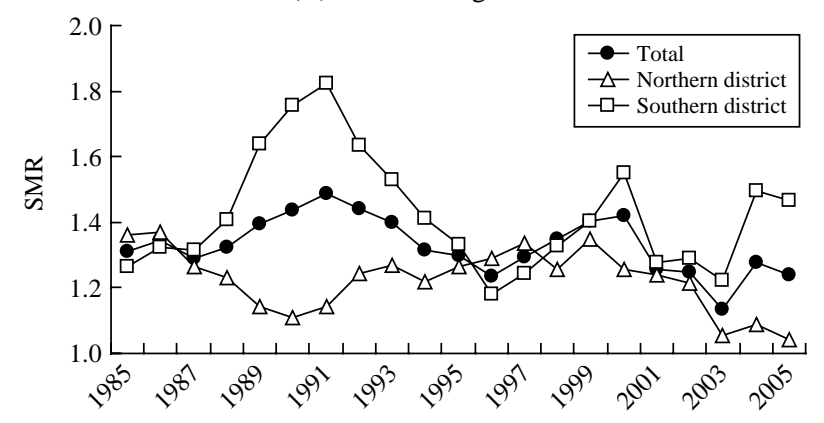

Fig. 5. Time trend of standardized mortality ratios (SMRs) (3-year moving averages) for lung cancer.

ings suggest the possibility that air pollution in the past affects the subsequent increase of lung cancer mortality among females. However, this study includes some major limitations that should be considered.

First, this study was an ecological study that was not conducted as a cohort study (Cohen and Pope, 1995; Greenland and Robins, 1994). We could not identify the population in the past when the level of air pollution was high, and there should have been considerable migration. However, the SMR of mesothelioma has been reported to be still high in the district where an asbestos cement factory had been located in the same city several decades ago (Kurumatani and Kumagai, 2008). Therefore, many of the current population are considered to have lived in the city for a long period.

Second, accurate information on the smoking habits of the subjects was not available (Katsouyanni et al., 1991; Jedrychowski et al., 1990; Vena, 1982). In the survey conducted by the municipal office in 2002 (Health and Welfare Bureau, 2003), the prevalence of current smokers was $43.2 \%$ for males and $10.5 \%$ for females, almost equal to the results of the national survey in 2002 (Ministry of Health, 2004) (43.4\% and $10.2 \%$, respectively). In the survey that had been conducted in this area in 1965-1966 (Hitosugi, 1968), the prevalence of smokers was reported to be $86.8 \%$ for 
Table 3. Correlation coefficients between standardized mortality ratios (SMRs) for lung cancer and the amounts of sulfur oxides.

\begin{tabular}{|c|c|c|c|c|c|c|c|c|c|}
\hline \multirow{2}{*}{ Lag years } & \multicolumn{3}{|c|}{ Total } & \multicolumn{3}{|c|}{ Northern district } & \multicolumn{3}{|c|}{ Southern district } \\
\hline & $\mathrm{r}$ & $\mathrm{p}$ & $\mathrm{N}$ & $\mathrm{r}$ & $\mathrm{p}$ & $\mathrm{N}$ & $\mathrm{r}$ & $\mathrm{p}$ & $\mathrm{N}$ \\
\hline \multicolumn{10}{|l|}{ Males } \\
\hline 15 & 0.037 & 0.869 & 22 & -0.305 & 0.168 & 22 & 0.254 & 0.254 & 22 \\
\hline 16 & 0.004 & 0.987 & 22 & -0.342 & 0.120 & 22 & 0.285 & 0.198 & 22 \\
\hline 17 & 0.061 & 0.789 & 22 & -0.273 & 0.218 & 22 & 0.313 & 0.156 & 22 \\
\hline 18 & 0.193 & 0.389 & 22 & -0.199 & 0.375 & 22 & 0.343 & 0.118 & 22 \\
\hline 19 & 0.257 & 0.248 & 22 & -0.090 & 0.690 & 22 & 0.294 & 0.184 & 22 \\
\hline 20 & 0.159 & 0.481 & 22 & -0.072 & 0.749 & 22 & 0.127 & 0.573 & 22 \\
\hline 21 & 0.087 & 0.701 & 22 & 0.029 & 0.898 & 22 & 0.000 & 0.999 & 22 \\
\hline 22 & 0.073 & 0.746 & 22 & 0.003 & 0.990 & 22 & -0.032 & 0.888 & 22 \\
\hline 23 & 0.184 & 0.413 & 22 & 0.124 & 0.583 & 22 & -0.021 & 0.927 & 22 \\
\hline 24 & 0.224 & 0.317 & 22 & 0.085 & 0.707 & 22 & -0.050 & 0.824 & 22 \\
\hline 25 & 0.259 & 0.257 & 21 & 0.200 & 0.384 & 21 & -0.130 & 0.573 & 21 \\
\hline 26 & 0.187 & 0.429 & 20 & 0.259 & 0.271 & 20 & -0.229 & 0.331 & 20 \\
\hline 27 & 0.146 & 0.550 & 19 & 0.412 & 0.080 & 19 & -0.277 & 0.250 & 19 \\
\hline 28 & 0.020 & 0.936 & 18 & 0.410 & 0.091 & 18 & -0.309 & 0.212 & 18 \\
\hline 29 & -0.078 & 0.766 & 17 & 0.464 & 0.061 & 17 & -0.425 & 0.089 & 17 \\
\hline 30 & -0.083 & 0.759 & 16 & 0.470 & 0.066 & 16 & -0.543 & 0.030 & 16 \\
\hline \multicolumn{10}{|l|}{ Females } \\
\hline 15 & 0.212 & 0.343 & 22 & 0.490 & 0.021 & 22 & -0.142 & 0.530 & 22 \\
\hline 16 & 0.163 & 0.469 & 22 & 0.508 & 0.016 & 22 & -0.190 & 0.396 & 22 \\
\hline 17 & 0.174 & 0.439 & 22 & 0.474 & 0.026 & 22 & -0.179 & 0.426 & 22 \\
\hline 18 & 0.192 & 0.393 & 22 & 0.364 & 0.096 & 22 & -0.061 & 0.788 & 22 \\
\hline 19 & 0.283 & 0.202 & 22 & 0.253 & 0.257 & 22 & 0.127 & 0.574 & 22 \\
\hline 20 & 0.375 & 0.086 & 22 & 0.131 & 0.561 & 22 & 0.371 & 0.089 & 22 \\
\hline 21 & 0.513 & 0.015 & 22 & 0.088 & 0.698 & 22 & 0.511 & 0.015 & 22 \\
\hline 22 & 0.551 & 0.008 & 22 & 0.096 & 0.672 & 22 & 0.474 & 0.026 & 22 \\
\hline 23 & 0.537 & 0.010 & 22 & 0.147 & 0.514 & 22 & 0.358 & 0.102 & 22 \\
\hline 24 & 0.491 & 0.020 & 22 & 0.123 & 0.586 & 22 & 0.235 & 0.292 & 22 \\
\hline 25 & 0.459 & 0.036 & 21 & 0.137 & 0.554 & 21 & 0.147 & 0.525 & 21 \\
\hline 26 & 0.474 & 0.035 & 20 & 0.220 & 0.352 & 20 & 0.147 & 0.537 & 20 \\
\hline 27 & 0.516 & 0.024 & 19 & 0.409 & 0.082 & 19 & 0.233 & 0.336 & 19 \\
\hline 28 & 0.583 & 0.011 & 18 & 0.589 & 0.010 & 18 & 0.372 & 0.129 & 18 \\
\hline 29 & 0.573 & 0.016 & 17 & 0.747 & 0.001 & 17 & 0.490 & 0.046 & 17 \\
\hline 30 & 0.509 & 0.044 & 16 & 0.922 & 0.000 & 16 & 0.520 & 0.039 & 16 \\
\hline
\end{tabular}

The SMRs for lung cancer and the amounts of sulfur oxides are shown by lag years.

males and $19.5 \%$ for females. The prevalence was also similar to the contemporary national survey. In addition, we could obtain information on neither exposure to environmental tobacco smoke (Hirayama, 1981) nor occupational exposure to pollutants (Jedrychowski et al., 1990; Vena, 1982). Since there had been many factories in the city, many persons might have been exposed to various pollutants, such as dust or asbestos, which are risk factors for lung cancer (Committee on Japan's Experience in the Battle against Air Pollution; Chairman: Sawa, 1997; Hitosugi, 1968). In the present study, the association between air pollution and lung cancer was significant only among females. The prevalence of smokers and occupational exposure to dust should be higher among males than among females, and lung cancer mortality among males is more than twice that among females. Therefore, we might not be able to detect any effects of air pollution on lung cancer mortality among males. This finding is consistent with the result of a previous study showing that the association between the level of air pollution and lung cancer mortality was larger among females than among males (Naess et al., 2007; Shimizu et al., 1979). In the previous studies, females were reported to have a greater risk associated with air pollution compared to males (Annesi-Maesano et al., 2003).

Third, the levels of air pollution in the past were evaluated using the amounts of sulfur oxides and dust fall. Although these amounts had been measured intermittently at various points in the city, they were strongly correlated with the concentrations of pollutants that were monitored continuously later. In recent years, the effects of fine particles, including diesel exhaust particles, on the incidence of lung cancer have become a 
Table 4. Correlation coefficients between standardized mortality ratios (SMRs) for lung cancer and the amounts of dust fall.

\begin{tabular}{|c|c|c|c|c|c|c|c|c|c|}
\hline \multirow{2}{*}{ Lag years } & \multicolumn{3}{|c|}{ Total } & \multicolumn{3}{|c|}{ Northern district } & \multicolumn{3}{|c|}{ Southern district } \\
\hline & $\mathrm{r}$ & $\mathrm{p}$ & $\mathrm{N}$ & $\mathrm{r}$ & $\mathrm{p}$ & $\mathrm{N}$ & $\mathrm{r}$ & $\mathrm{p}$ & $\mathrm{N}$ \\
\hline \multicolumn{10}{|l|}{ Males } \\
\hline 15 & 0.025 & 0.911 & 22 & -0.390 & 0.073 & 22 & 0.278 & 0.210 & 22 \\
\hline 16 & 0.062 & 0.785 & 22 & -0.361 & 0.099 & 22 & 0.304 & 0.169 & 22 \\
\hline 17 & 0.108 & 0.634 & 22 & -0.305 & 0.168 & 22 & 0.311 & 0.159 & 22 \\
\hline 18 & 0.165 & 0.463 & 22 & -0.210 & 0.348 & 22 & 0.308 & 0.163 & 22 \\
\hline 19 & 0.180 & 0.422 & 22 & -0.136 & 0.545 & 22 & 0.273 & 0.219 & 22 \\
\hline 20 & 0.179 & 0.425 & 22 & -0.040 & 0.860 & 22 & 0.190 & 0.398 & 22 \\
\hline 21 & 0.132 & 0.559 & 22 & 0.060 & 0.791 & 22 & 0.084 & 0.712 & 22 \\
\hline 22 & 0.150 & 0.505 & 22 & 0.223 & 0.319 & 22 & -0.002 & 0.994 & 22 \\
\hline 23 & 0.155 & 0.492 & 22 & 0.377 & 0.084 & 22 & -0.113 & 0.616 & 22 \\
\hline 24 & 0.250 & 0.261 & 22 & 0.576 & 0.005 & 22 & -0.231 & 0.302 & 22 \\
\hline 25 & 0.274 & 0.230 & 21 & 0.601 & 0.004 & 21 & -0.336 & 0.136 & 21 \\
\hline 26 & 0.262 & 0.264 & 20 & 0.610 & 0.004 & 20 & -0.428 & 0.060 & 20 \\
\hline 27 & 0.019 & 0.939 & 19 & 0.429 & 0.067 & 19 & -0.531 & 0.019 & 19 \\
\hline 28 & -0.129 & 0.611 & 18 & 0.383 & 0.117 & 18 & -0.597 & 0.009 & 18 \\
\hline 29 & -0.145 & 0.579 & 17 & 0.304 & 0.235 & 17 & -0.522 & 0.032 & 17 \\
\hline 30 & 0.140 & 0.606 & 16 & 0.371 & 0.157 & 16 & -0.381 & 0.145 & 16 \\
\hline \multicolumn{10}{|l|}{ Females } \\
\hline 15 & 0.130 & 0.563 & 22 & 0.496 & 0.019 & 22 & -0.042 & 0.852 & 22 \\
\hline 16 & 0.114 & 0.614 & 22 & 0.522 & 0.013 & 22 & -0.103 & 0.648 & 22 \\
\hline 17 & 0.109 & 0.631 & 22 & 0.475 & 0.026 & 22 & -0.082 & 0.717 & 22 \\
\hline 18 & 0.194 & 0.386 & 22 & 0.421 & 0.051 & 22 & -0.023 & 0.920 & 22 \\
\hline 19 & 0.316 & 0.152 & 22 & 0.319 & 0.148 & 22 & 0.085 & 0.706 & 22 \\
\hline 20 & 0.483 & 0.023 & 22 & 0.252 & 0.258 & 22 & 0.225 & 0.315 & 22 \\
\hline 21 & 0.587 & 0.004 & 22 & 0.210 & 0.349 & 22 & 0.366 & 0.094 & 22 \\
\hline 22 & 0.574 & 0.005 & 22 & 0.278 & 0.210 & 22 & 0.431 & 0.045 & 22 \\
\hline 23 & 0.499 & 0.018 & 22 & 0.329 & 0.135 & 22 & 0.448 & 0.036 & 22 \\
\hline 24 & 0.392 & 0.071 & 22 & 0.338 & 0.124 & 22 & 0.456 & 0.033 & 22 \\
\hline 25 & 0.290 & 0.202 & 21 & 0.317 & 0.161 & 21 & 0.447 & 0.042 & 21 \\
\hline 26 & 0.290 & 0.215 & 20 & 0.321 & 0.167 & 20 & 0.440 & 0.052 & 20 \\
\hline 27 & 0.387 & 0.102 & 19 & 0.311 & 0.195 & 19 & 0.389 & 0.100 & 19 \\
\hline 28 & 0.572 & 0.013 & 18 & 0.259 & 0.299 & 18 & 0.318 & 0.199 & 18 \\
\hline 29 & 0.771 & 0.000 & 17 & 0.366 & 0.148 & 17 & 0.150 & 0.567 & 17 \\
\hline 30 & 0.847 & 0.000 & 16 & 0.463 & 0.071 & 16 & -0.050 & 0.854 & 16 \\
\hline
\end{tabular}

The SMRs for lung cancer and the amounts of dust fall are shown by lag years.

major concern (Nawrot et al., 2007; Laden et al., 2006; Pope et al., 2002). However, the concentrations of fine particles were not measured in the 1960s. In the present analysis, the amounts of sulfur oxides and dust fall that had been measured in the 1960s were used as the indices of air pollution. The concentrations and constituents of fine particles should be further evaluated. In Amagasaki City, an asbestos cement factory had also been located, and the risk of mesothelioma was reported to be high among residents around the factory (Kurumatani and Kumagai, 2008). However, it is presumed that the affected area was limited to about $2 \mathrm{~km}$ from the factory. On the other hand, this study showed an increased risk of lung cancer mortality in a rather wide area covering the entire city.

Fourth, we calculated expected deaths using national data on mortality for lung cancer, which has consistent- ly increased during the past several decades. The concentrations of air pollution were very high in the 1960s and 1970s not only in Amagasaki City, but also in other industrial cities in Japan. Therefore, the comparison of lung cancer mortality with all Japanese who died due to lung cancer may lead to underestimation of the risk of air pollution.

It has been recognized that air pollution is associated with an increased prevalence of bronchial asthma and chronic obstructive pulmonary disease (COPD) (Committee on Japan's Experience in the Battle against Air Pollution; Chairman: Sawa, 1997; Imai et al., 1986). In Yokkaichi, an industrial city with a severe level of air pollution in the 1960s, as in Amagasaki, the mortality of bronchial asthma and COPD increased as a result of worsening air pollution. The mortality due to bronchial asthma decreased promptly in response to 
decreased air pollution, but the mortality due to COPD decreased with a time lag of 4 or 5 years (Imai et al., 1986). A recent study (Guo et al., 2008) showed that mortality and life expectancy in patients with these diseases were still affected, despite the fact that the level of air pollution had already improved. In addition, the present study showed the association between the level of air pollution and lung cancer after considering the lag time of 20-30 years, especially in the southern district of Amagasaki City where the levels of air pollution were markedly higher. Thus, severe air pollution might produce prolonged effects on human health after the level had decreased.

\section{CONCLUSIONS}

Past severe air pollution in an industrial city appears to be related to the subsequent increase in lung cancer mortality. In many industrial cities, the levels of air pollution had been high in the past. Since lung cancer might occur several decades after exposure to risk factors, the effects of air pollution should be evaluated over a long period after the levels have decreased.

\section{ACKNOWLEDGEMENTS}

Most of vital statistics and air pollution data in the past were available from the Amagasaki Municipal Archives, Japan. The authors thank the staffs of the archive for their helpful supports.

\section{REFERENCES}

Annesi-Maesano I., N. Agabiti, R. Pistelli, M.F. Couilliot, and F. Forastiere (2003) Subpopulations at increased risk of adverse health outcomes from air pollution. Eur. Respir. J. Suppl., 40, 57s-63s.

Archer V.E. (1990) Air pollution and fatal lung disease in three Utah counties. Arch. Environ. Health, 45(6), 325334.

Barbone F., M. Bovenzi, F. Cavallieri, and G. Stanta (1995) Air pollution and lung cancer in Trieste, Italy. Am. J. Epidemiol., 141(12), 1161-1169.

Buffler P.A., S.P. Cooper, S. Stinnett, C. Contant, S. Shirts, R.J. Hardy, V. Agu, B. Gehan, and K. Burau (1988) Air pollution and lung cancer mortality in Harris County, Texas, 1979-1981. Am. J. Epidemiol., 128(4), 683699.

Cohen A.J. and C.A. Pope, 3rd (1995) Lung cancer and air pollution. Environ. Health Perspect., 103 Suppl 8, 219-224.

Department of Environment, Amagasaki City (1961-1993) Reports on environment of Amagasaki City in 1960-
1992 [in Japanese], Amagasaki City Printing Office, Amagasaki.

Dockery D.W., C.A. Pope, 3rd, X. Xu, J.D. Spengler, J.H. Ware, M.E. Fay, B.G. Ferris, Jr., and F.E. Speizer (1993) An association between air pollution and mortality in six U.S. cities. N. Engl. J. Med., 329(24), 17531759.

Doll R., R. Peto, K. Wheatley, R. Gray, and I. Sutherland (1994) Mortality in relation to smoking: 40 years' observations on male British doctors. BMJ, 309, 901-911.

Filleul L., V. Rondeau, S. Vandentorren, N. Le Moual, A. Cantagrel, I. Annesi-Maesano, D. Charpin, C. Declercq, F. Neukirch, C. Paris, D. Vervloet, P. Brochard, J.F. Tessier, F. Kauffmann, and I. Baldi (2005) Twenty five year mortality and air pollution: results from the French PAARC survey. Occup. Environ. Med., 62, 453-460.

Gallus S., E. Negri, P. Boffetta, J.K. McLaughlin, C. Bosetti, and C. La Vecchia (2008) European studies on long-term exposure to ambient particulate matter and lung cancer. Eur. J. Cancer Prev., 17(3), 191-194.

Greenland S. and J. Robins (1994) Invited commentary: ecologic studies-biases, misconceptions, and counterexamples. Am. J. Epidemiol., 139(8), 747-760.

Guo P., K. Yokoyama, M. Suenaga, and H. Kida (2008) Mortality and life expectancy of Yokkaichi asthma patients, Japan: late effects of air pollution in 1960-70s. Environ. Health, 7:8, doi:10.1186/1476-069x-7-8.

Health and Welfare Bureau, Amagasaki City (1985-2008) Vital statistics of Amagasaki City in 1983-2006 [in Japanese], Amagasaki Public Health Center, Amagasaki.

Health and Welfare Bureau, Amagasaki City (2003) A survey on health promotion of an Amagasaki citizen [in Japanese], Amagasaki City Printing Office, Amagasaki.

Henderson B.E., R.J. Gordon, H. Menck, J. Soohoo, S.P. Martin, and M.C. Pike (1975) Lung cancer and air pollution in southcentral Los Angeles County. Am. J. Epidemiol., 101(6), 477-488.

Hirayama T. (1981) Non-smoking wives of heavy smokers have a higher risk of lung cancer: a study from Japan. Br. Med. J., 282, 183-185.

Hitosugi M. (1968) Epidemiological study of lung cancer with special reference to the effect of air pollutiuon and smoking habit. Bulletin of the Institute of Public Health, 17, 237-256.

Hoek G., B. Brunekreef, S. Goldbohm, P. Fischer, and P.A. van den Brandt (2002) Association between mortality and indicators of traffic-related air pollution in the Netherlands: a cohort study. Lancet, 360, 1203-1209.

Imai M., K. Yoshida, and M. Kitabatake (1986) Mortality from asthma and chronic bronchitis associated with changes in sulfur oxides air pollution. Arch. Environ. Health, 41(1), 29-35.

Iwai K., S. Mizuno, Y. Miyasaka, and T. Mori (2005) Correlation between suspended particles in the environmental air and causes of disease among inhabitants: cross-sectional studies using the vital statistics and air pollution data in Japan. Environ. Res., 99, 106-117. 
Jedrychowski W., H. Becher, J. Wahrendorf, and Z. BasaCierpialek (1990) A case-control study of lung cancer with special reference to the effect of air pollution in Poland. J. Epidemiol. Community Health, 44(2), 114120.

Katsouyanni K., D. Trichopoulos, A. Kalandidi, P. Tomos, and E. Riboli (1991) A case-control study of air pollution and tobacco smoking in lung cancer among women in Athens. Prev. Med., 20, 271-278.

Kurumatani N. and S. Kumagai (2008) Mapping the risk of mesothelioma due to neighborhood asbestos exposure. Am. J. Respir. Crit. Care Med., 178, 624-629.

Laden F., J. Schwartz, F.E. Speizer, and D.W. Dockery (2006) Reduction in fine particulate air pollution and mortality: Extended follow-up of the Harvard Six Cities study. Am. J. Respir. Crit. Care Med., 173, 667-672.

Marugame T. and T. Sobue (2004) Mortality trend of mouth and pharynx, esophagus, stomach, larynx and lung cancer in Japan by birth cohort. Jpn. J. Clin. Oncol., 34(7), 432-434.

Marugame T., T. Sobue, H. Satoh, S. Komatsu, Y. Nishino, H. Nakatsuka, T. Nakayama, T. Suzuki, T. Takezaki, K. Tajima, and S. Tominaga (2005) Lung cancer death rates by smoking status: comparison of the ThreePrefecture Cohort study in Japan to the Cancer Prevention Study II in the USA. Cancer Sci., 96(2), 120-126.

Ministry of Health, Labor, and Welfare, Japan (2004) The National Nutrition Survey, 2002 [in Japanese], Daiichi Shuppan Press, Tokyo.

Naess O., P. Nafstad, G. Aamodt, B. Claussen, and P. Rosland (2007) Relation between concentration of air pollution and cause-specific mortality: four-year exposures to nitrogen dioxide and particulate matter pollutants in 470 neighborhoods in Oslo, Norway. Am. J. Epidemiol., 165(4), 435-443.

Nafstad P., L.L. Haheim, B. Oftedal, F. Gram, I. Holme, I. Hjermann, and P. Leren (2003) Lung cancer and air pollution: a 27 year follow up of 16209 Norwegian men. Thorax, 58(12), 1071-1076.

Nawrot T.S., K. Nackaerts, P.H. Hoet, and B. Nemery (2007) Lung cancer mortality and fine particulate air pollution in Europe. Int. J. Cancer, 120(8), 1825-1826; author reply 1827.

Nyberg F., P. Gustavsson, L. Järup, T. Bellander, N. Berglind, R. Jakobsson, and G. Pershagen (2000) Urban air pollution and lung cancer in Stockholm. Epidemiology, 11(5), 487-495.
Parodi S., E. Stagnaro, C. Casella, A. Puppo, E. Daminelli, V. Fontana, F. Valerio, and M. Vercelli (2005) Lung cancer in an urban area in Northern Italy near a coke oven plant. Lung Cancer, 47(2), 155-164.

Pope C.A., 3rd, R.T. Burnett, M.J. Thun, E.E. Calle, D. Krewski, K. Ito, and G.D. Thurston (2002) Lung cancer, cardiopulmonary mortality, and long-term exposure to fine particulate air pollution. JAMA, 287(9), 11321141.

Sawa T. (Committee on Japan's Experience in the Battle against Air Pollution: Chairman) (1997) Japan's Experience in the Battle against Air Pollution, The Pollution-Related Health Damage Compensation and Prevention Association, Tokyo.

Shimizu H., S. Tominaga, N. Nakagawa, and T. Kuroishi (1979) An epidemiological study on lung cancer. The relationship between the lung cancer mortality and air pollution by ward in a large city [in Japanese]. Journal of Japan Society of Air Pollution, 14, 324-333.

Stevens R.G. and S.H. Moolgavkar (1984) A cohort analysis of lung cancer and smoking in British males. Am. J. Epidemiol., 119(4), 624-641.

Thun M.J., C. Day-Lally, D.G. Myers, E.E. Calle, W.D. Flanders, B.P. Zhu, M.M. Namboodiri, and C.W. Heath (1997) Trends in tobacco smoking and mortality from cigarette use in Cancer Prevention Studies I (1959 through 1965) and II (1982 through 1988). National Cancer Institute, Smoking and Tobacco Control, Monograph 8: Changes in Cigarette-Related Disease Risks and their Implication for Prevention and Control., NIH Publication, Washington D.C., pp. 305-382.

Vena J.E. (1982) Air pollution as a risk factor in lung cancer. Am. J. Epidemiol., 116(1), 42-56.

Vineis P., G. Hoek, M. Krzyzanowski, F. Vigna-Taglianti, F. Veglia, L. Airoldi, H. Autrup, A. Dunning, S. Garte, P. Hainaut, C. Malaveille, G. Matullo, K. Overvad, O. Raaschou-Nielsen, F. Clavel-Chapelon, J. Linseisen, H. Boeing, A. Trichopoulou, D. Palli, M. Peluso, V. Krogh, R. Tumino, S. Panico, H.B. Bueno-De-Mesquita, P.H. Peeters, E.E. Lund, C.A. Gonzalez, C. Martinez, M. Dorronsoro, A. Barricarte, L. Cirera, J.R. Quiros, G. Berglund, B. Forsberg, N.E. Day, T.J. Key, R. Saracci, R. Kaaks, and E. Riboli (2006) Air pollution and risk of lung cancer in a prospective study in Europe. Int. J. Cancer, 119(1), 169-174.

(Received 17 November 2008, accepted 5 April 2009) 